\title{
Sex differences in comorbidity at diagnosis of multiple sclerosis
}

\author{
A population-based study \\ OPEN
}

Ruth Ann Marrie, MD, $\mathrm{PhD}$

Scott B. Patten, MD, $\mathrm{PhD}$

Helen Tremlett, PhD

Christina Wolfson, PhD

Sharon Warren, PhD

Lawrence W. Svenson, $\mathrm{PhD}$

Nathalie Jette, MD, MSc John Fisk, PhD

For the CIHR Team in the Epidemiology and Impact of Comorbidity on Multiple Sclerosis

Correspondence to Dr. Marrie:

rmarrie@hsc.mb.ca

Editorial, page 1275

Supplemental data at Neurology.org

\section{ABSTRACT}

Objective: To determine the prevalence of comorbidity in the multiple sclerosis (MS) population at the time of MS diagnosis. We also compared the prevalence of comorbidity in the MS population to that in a matched cohort from the general population.

Methods: Using population-based administrative health data from 4 Canadian provinces, we identified 23,382 incident MS cases and 116,638 age-, sex-, and geographically matched controls. We estimated the prevalence of hypertension, diabetes, hyperlipidemia, heart disease, chronic lung disease, epilepsy, fibromyalgia, inflammatory bowel disease, depression, anxiety, bipolar disorder, and schizophrenia at MS diagnosis using validated case definitions. We compared the populations using rate ratios.

Results: Of the MS cases, $16,803(71.9 \%)$ were female. The most prevalent comorbidity was depression (19.1\%). Compared to the matched population, all comorbidities except hyperlipidemia were more common in the MS population. Relative to the matched populations, the prevalence of hypertension was $16 \%$ higher for women with MS and $48 \%$ higher for men with MS, thus there was a disproportionately higher prevalence of hypertension in men with MS than women. Men with MS also had a disproportionately higher prevalence than women with MS for diabetes, epilepsy, depression, and anxiety.

Conclusions: Comorbidity is more common than expected in MS, even around the time of diagnosis. The prevalence of psychiatric comorbidity is particularly high and highlights the need for clinical attention to this issue. The observed sex-specific differences in the burden of comorbidity in MS, which differ from those in the matched population, warrant further investigation. Neurology ${ }^{\circledR} 2016 ; 86: 1279-1286$

\section{GLOSSARY}

ALD = affections de longue durée; ICD-9 = International Classification of Diseases-9; ICD-10 = International Classification of Diseases-10; $\mathbf{M S}=$ multiple sclerosis.

In many chronic diseases, comorbidity is associated with reduced quality of life, ${ }^{1}$ increased health care utilization, and increased mortality. ${ }^{2}$ For example, vascular comorbidity is associated with more rapid cognitive decline in Alzheimer disease. ${ }^{3}$ Some studies suggest that in multiple sclerosis (MS) comorbidity is associated with diagnostic delays and greater disability at MS diagnosis, ${ }^{4}$ and increased risks of disability progression. ${ }^{5}$ However, the epidemiology of comorbidity in MS, including sex-specific differences in the incidence or prevalence of comorbidity, remains poorly understood. ${ }^{6}$

As new disease-modifying therapies for MS emerge for which risks of adverse events differ in the presence of comorbidity, ${ }^{7}$ it becomes increasingly important to understand the frequency of

\footnotetext{
From the Departments of Internal Medicine (R.A.M.) and Community Health Sciences (R.A.M.), University of Manitoba; Department of Community Health Sciences (S.B.P., L.W.S., N.J.), Institute for Public Health (N.J.), Department of Clinical Neurosciences (N.J.), and Hotchkiss Brain Institute (N.J.), University of Calgary; Department of Medicine (Neurology) (H.T.), University of British Columbia, Vancouver; Department of Epidemiology and Biostatistics and Occupational Health (C.W.), McGill University, Montreal; Faculty of Rehabilitation Medicine (S.W.) and School of Public Health (L.W.S.), University of Alberta, Edmonton; Surveillance and Assessment (L.W.S.), Alberta Health, Edmonton; and Departments of Psychiatry and Medicine (J.F.), Dalhousie University, Halifax, Canada. Coinvestigators are listed on the Neurology ${ }^{\circledR}$ Web site at Neurology.org.

Go to Neurology.org for full disclosures. Funding information and disclosures deemed relevant by the authors, if any, are provided at the end of the article. The Article Processing Charge was paid by the Canadian Institutes of Health Research.

This is an open access article distributed under the terms of the Creative Commons Attribution-NonCommercial-NoDerivatives License 4.0 (CC BY-NC-ND), which permits downloading and sharing the work provided it is properly cited. The work cannot be changed in any way or used commercially.
} 
comorbidity throughout the disease course, particularly at clinically relevant time points such as at diagnosis. Findings regarding the prevalence of comorbidity at MS diagnosis conflict. $^{8,9}$ One self-report study conducted in the United States found that comorbidity affected more than $35 \%$ of respondents at diagnosis. ${ }^{9}$ However, a study in France that focused on persons with MS onset before age 45 years and used a national disability register found that only $3 \%$ of the MS population had a comorbidity at diagnosis. ${ }^{8}$

Using population-based administrative data, we aimed to determine the prevalence of comorbidity in the MS population at MS diagnosis, and whether this differed by sex. We also compared the prevalence of comorbidity in the MS population to that in a matched cohort from the general population.

METHODS Administrative data. We used administrative health data from 4 Canadian provinces, including British Columbia, Manitoba, Quebec, and Nova Scotia. These provinces were selected based on the feasibility of accessing the necessary administrative data, and include nearly $43 \%$ of the Canadian population (http://www. statcan.gc.ca/tables-tableaux/sum-som/101/cst01/demo02a-eng.htm). All Canadian provinces administer a publicly funded, universally available health care system ${ }^{10}$ and maintain computerized records related to the provision of these services. These records include a population registry that captures dates of birth, death, and health care coverage; hospital discharge abstracts that capture dates of admission and discharge and discharge diagnoses; and physician visits that capture the date of service and diagnosis. ${ }^{1-13}$ Due to provincial privacy regulations that prevent individual-level data from leaving the province of origin, analyses were performed in parallel at each site, then the data were aggregated by age and sex groupings.

Standard protocol approvals, registrations, and patient consents. In each province, we obtained ethics approval and provincial approval to access administrative data.

Study populations. In each province, we applied an administrative case definition for MS that had been validated and performed similarly in Manitoba and Nova Scotia. ${ }^{14,15}$ Anyone aged $\geq 20$ years with $\geq 3$ hospital or physician claims for MS (ICD-9/10 codes 340/G35) during the study period was classified as having MS. To identify incident cases of MS, we used a 5-year run-in period; thus if administrative data were available in 1990, the earliest incident cases could be identified in $1995 .{ }^{14,15}$

We identified a cohort from the general population, matched on sex, year of birth, and region of residence (postal code or first 3 digits of postal code if unable to match on full postal code). Statistical efficiency is optimized at 4 to 6 matched controls; therefore we obtained up to 5 matches for each case after excluding anyone with any diagnostic codes (ICD-9/10) for demyelinating disease: optic neuritis (377.3/H46), acute transverse myelitis (323.82/G37), acute disseminated encephalomyelitis (323/G36.9), demyelinating disease of CNS unspecified (341.9/G37.8), other acute disseminated demyelination (G36), MS (340/G35), or neuromyelitis optica (341.0/G36.0). For each person with MS, we assigned the date of the first health claim for demyelinating disease as the date of diagnosis, and the same (index) date was assigned to matched controls.

Comorbidities. We selected several comorbidities for study that had been evaluated in earlier studies of comorbidity at diagnosis of MS, ${ }^{8,9}$ and that our prior work had indicated could be accurately identified using administrative case definitions in the MS population. ${ }^{16-19}$ These comorbidities were hypertension, diabetes, hyperlipidemia, heart disease, chronic lung disease, epilepsy, fibromyalgia, inflammatory bowel disease, depression, anxiety, bipolar disorder, and schizophrenia. We did not evaluate cancer because of the expected low prevalence of this condition at MS diagnosis, and due to the need to access provincial cancer registries to optimize identification of cancer. We applied the validated administrative case definitions for comorbidity to the MS and matched control populations in each province (table e- 1 on the Neurology ${ }^{\circledR}$ Web site at Neurology.org). These definitions specified the number of years of data to be used, the ICD-9/10 codes, and the number of hospital or physician claims required to meet the case definition. For hospital claims, we used all available diagnoses. For physician claims, we had previously established that using all available diagnoses (when available) from physician claims had little influence on the performance of the case definitions, ${ }^{20}$ and as some provinces only capture one diagnosis per physician claim, we used only the first listed diagnosis for each physician claim.

Prevalence. As the comorbidities represent chronic conditions, once a person met the case definition for a comorbidity, he or she was considered to be affected in all subsequent years while resident in the province. ${ }^{21}$ We determined the crude prevalence of the comorbidity in the year of MS diagnosis or the index date for matched controls using the midyear population figures from the provincial population registry for denominators in the calculations. To ensure adequate cell sizes and stable estimates, we aggregated crude prevalence data across the study period. To facilitate comparisons to the study from France, which restricted its analysis to persons under age 45 years at diagnosis, ${ }^{8}$ we present age-specific rates for persons aged $20-44,45-59$, and more than 60 years. We also present sex-specific estimates. Cell sizes $<5$ were suppressed as per the privacy agreements for data access. A matched analysis is not needed for a matched cohort design. Adjustment is not needed to control for confounding due to the matching variables if follow-up time is the same in both cohorts. ${ }^{22}$ Therefore, we compared the MS and general population cohorts using rate ratios and $95 \%$ confidence intervals. ${ }^{22}$ We report the time from comorbidity diagnosis to the index date using means and standard deviations, as we could not aggregate medians across provinces without individual level data.

Sensitivity analyses. To address the possible effect of increased health care utilization due to unrecognized symptoms of MS before MS diagnosis, ${ }^{23}$ we repeated the analysis in individuals with an index year $\geq 2000$ who had 10 years of administrative data before the index year. This allowed us to apply the comorbidity case definitions 5 years before the index date (as some definitions required 5 years of data to identify a comorbidity, this required 10 years of data). We report findings at the index year and at 5 years before the index year.

Analyses were performed using SAS V9.3 (SAS Institute Inc., Cary, NC).

RESULTS We identified 23,382 incident MS cases and 116,638 matched controls (table 1). Of the MS cases, 16,803 (71.9\%) were female. At diagnosis, the 


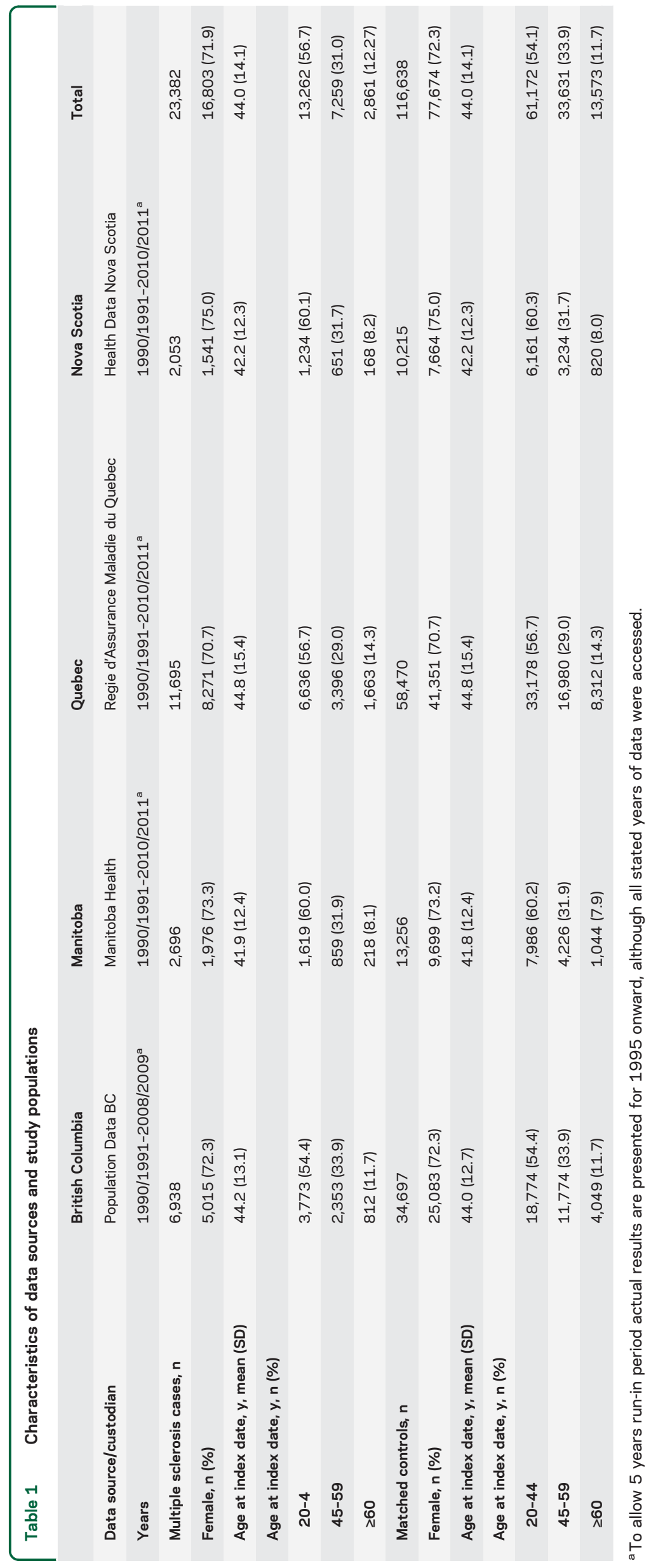

most prevalent comorbidity overall was depression (19.1\%), followed by hypertension (15.2\%) (table 2).

Among psychiatric comorbidities, prevalence varied somewhat across age groups, but without a consistent pattern (tables e-2 to e-5). Among physical comorbidities, the prevalence of diabetes, hypertension, hyperlipidemia, ischemic heart disease, chronic lung disease, and epilepsy increased with age (tables e-6 to e-13).

In both populations, depression, anxiety, and bipolar disorder were more prevalent in women than men, while schizophrenia was less common in women (table 3). Among physical comorbidities, fibromyalgia was more common in women. Inflammatory bowel disease and chronic lung disease were more common in women but this did not reach statistical significance for inflammatory bowel disease. All other comorbidities were less common in women than men.

Comparisons. Compared to the matched controls, all psychiatric comorbidities were more common in the MS population. Similarly, all physical comorbidities except hyperlipidemia were more common in the MS population at the index date (table 2). Among physical comorbidities, those for which rate ratios were 1.50 or higher included fibromyalgia, inflammatory bowel disease, epilepsy, and bipolar disorder. The mean years between comorbidity diagnosis and the index date are shown in table 4.

For some comorbidities, the strengths of the associations differed by sex or age (tables e-2 to e-13). The associations between comorbidity and population were modified by sex for hypertension, diabetes, chronic lung disease, epilepsy, depression, anxiety, bipolar disorder, and schizophrenia (table 3). Among women, the prevalence of hypertension was 16\% higher in the MS than the matched population. Among men, however, the prevalence of hypertension was $48 \%$ higher in the MS than in the matched population, indicating a disproportionately higher prevalence of hypertension in men with MS than women. Findings were similar for diabetes, epilepsy, depression, and anxiety, with men again having disproportionately higher prevalence than women. With respect to chronic lung disease, the prevalence was 39\% higher among women with MS than among women without MS, but only 21\% higher among men with MS than men without MS. Thus there was a disproportionately higher prevalence of chronic lung disease among women with MS than men.

For diabetes, the rate ratios comparing the MS and matched populations were higher among those aged 20-44 years than among those aged $\geq 45$ years (table e-6). We did not identify age group by population interactions for the other comorbidities.

Sensitivity analyses. The prevalence of all comorbidities was lower in both populations 5 years before MS 
Table 2 Crude prevalence of comorbidity in the MS population at diagnosis compared to matched controls

\begin{tabular}{lllll} 
Comorbidity & MS $(\mathbf{n}=23,382), \mathbf{n}(\%)$ & $\begin{array}{l}\text { Matches } \\
(\mathbf{n}=116,638), \mathbf{n}(\%)\end{array}$ & RR (95\% CI) & $p$ Value \\
\hline Hypertension & $3,547(15.2)$ & $15,088(12.9)$ & $1.17(1.13-1.21)$ & $<0.0001$ \\
\hline Diabetes & $1,330(5.69)$ & $5,669(4.86)$ & $1.17(1.10-1.24)$ & $<0.0001$ \\
\hline Ischemic heart disease & $1,521(6.50)$ & $5,845(5.01)$ & $1.30(1.23-1.37)$ & $<0.0001$ \\
\hline Hyperlipidemia & $1,610(6.89)$ & $7,810(6.70)$ & $1.03(0.98-1.08)$ & 0.99 \\
\hline Fibromyalgia & $306(1.31)$ & $532(0.46)$ & $2.87(2.49-3.30)$ & $<0.0001$ \\
\hline Inflammatory bowel disease & $131(0.56)$ & $390(0.30)$ & $1.68(1.38-2.04)$ & $<0.0001$ \\
\hline Chronic lung disease & $2,920(12.1)$ & $10,856(9.14)$ & $1.34(1.29-1.39)$ & $<0.0001$ \\
\hline Epilepsy & $451(1.93)$ & $1,034(0.89)$ & $2.18(1.95-2.43)$ & $<0.0001$ \\
\hline Depression & $4,464(19.1)$ & $10,936(9.38)$ & $2.04(1.97-2.10)$ & $<0.0001$ \\
\hline Anxiety & $2,594(11.1)$ & $8,035(6.89)$ & $1.61(1.54-1.68)$ & $<0.0001$ \\
\hline Bipolar disorder & $736(3.15)$ & $1,973(1.69)$ & $1.86(1.71-2.02)$ & $<0.0001$ \\
\hline Schizophrenia & $251(1.07)$ & $947(0.81)$ & $1.32(1.15-1.52)$ & $<0.0001$ \\
\hline
\end{tabular}

Abbreviations: $\mathrm{Cl}=$ confidence interval; $\mathrm{MS}=$ multiple sclerosis; $\mathrm{RR}=$ rate ratio.

diagnosis (index date), but the associations between population and comorbidity were unchanged (table 5).

DISCUSSION In this population-based study of 23,382 Canadians with incident MS and 166,638 matches from the general population, we found that comorbidity was common at MS diagnosis, particularly depression. The burden of comorbidity was higher with increasing age at diagnosis, consistent with known associations of comorbidity with age in the general population. ${ }^{24}$ The prevalence of all psychiatric comorbidities and nearly all physical comorbidities was more common in the MS population than in the matched population. The

Table 3 Sex-specific crude prevalence of comorbidity at diagnosis in the MS and matched populations

\begin{tabular}{|c|c|c|c|c|c|c|c|c|}
\hline \multirow[b]{2}{*}{$\begin{array}{l}\text { Comorbidity, } \\
\text { n (\%) }\end{array}$} & \multicolumn{3}{|l|}{ MS population } & \multicolumn{3}{|c|}{ Matched population } & \multicolumn{2}{|l|}{ MS: matched } \\
\hline & $\begin{array}{l}\text { Female } \\
(n=16,803)\end{array}$ & $\begin{array}{l}\text { Male } \\
(n=6,579)\end{array}$ & $\begin{array}{l}\text { Female: male } \\
\text { ratio }(95 \% \mathrm{Cl})\end{array}$ & $\begin{array}{l}\text { Female } \\
\text { (n=83,797) }\end{array}$ & $\begin{array}{l}\text { Male } \\
(n=32,841)\end{array}$ & $\begin{array}{l}\text { Female: male } \\
\text { ratio }(95 \% \mathrm{Cl})\end{array}$ & $\begin{array}{l}\text { Female: female } \\
\text { ratio }(95 \% \mathrm{Cl})\end{array}$ & $\begin{array}{l}\text { Male: male } \\
\text { ratio }(95 \% \mathrm{Cl})\end{array}$ \\
\hline Hypertension & 2,394 (14.2) & $1,413(21.5)$ & $0.66(0.63-0.70)$ & $10,320(12.3)$ & $4,768(14.5)$ & $0.85^{\mathrm{a}}(0.82-0.88)$ & $1.16(1.11-1.21)$ & $1.48(1.40-1.56)$ \\
\hline Diabetes & $812(4.83)$ & $518(7.87)$ & $0.61(0.55-0.68)$ & $3,690(4.4)$ & $1,979(6.03)$ & $0.73^{b}(0.69-0.77)$ & $1.10(1.02-1.18)$ & 1.31 (1.19-1.43) \\
\hline Heart disease & 843 (5.02) & 678 (10.3) & $0.49(0.44-0.54)$ & $3,140(3.75)$ & $2,705(8.24)$ & $0.45(0.42-0.49)$ & $1.34(1.24-1.44)$ & $1.25(1.16-1.36)$ \\
\hline Hyperlipidemia & 942 (5.61) & 668 (10.1) & $0.55(0.50-0.61)$ & $4,584(5.47)$ & 3,225 (9.82) & $0.56(0.52-0.60)$ & $1.02(0.96-1.10)$ & $1.03(0.96-1.12)$ \\
\hline Fibromyalgia & $258(1.54)$ & $48(0.73)$ & $2.10(1.55-2.86)$ & $454(0.54)$ & $78(0.24)$ & $2.28(1.79-2.90)$ & $2.83(2.43-3.30)$ & $3.07(2.15-4.40)$ \\
\hline $\begin{array}{l}\text { Inflammatory } \\
\text { bowel disease }\end{array}$ & 99 (0.59) & $32(0.49)$ & $1.21(0.81-1.80)$ & $32(0.49)$ & $93(0.28)$ & $1.25(0.99-1.58)$ & $1.66(1.32-2.09)$ & $1.72(1.15-2.56)$ \\
\hline $\begin{array}{l}\text { Chronic lung } \\
\text { disease }\end{array}$ & 2,269 (13.5) & $651(9.90)$ & $1.36(1.26-1.48)$ & $8,160(9.74)$ & 2,696 (8.21) & $1.19^{c}(1.14-1.24)$ & 1.39 (1.33-1.45) & $1.21(1.11-1.31)$ \\
\hline Epilepsy & 331 (1.97) & $170(2.58)$ & $0.76(0.64-0.92)$ & 735 (0.88) & $299(0.91)$ & $0.96^{d}(0.84-1.10)$ & 2.25 (1.97-2.55) & $2.84(2.36-3.42)$ \\
\hline Depression & 2,869 (17.1) & 695 (10.6) & $1.62(1.50-1.75)$ & 9,025 (10.8) & 1,911 (5.82) & $1.85^{\mathrm{e}}(1.76-1.94)$ & 1.59 (1.53-1.65) & $1.82(1.67-1.97)$ \\
\hline Anxiety & 2,060 (12.3) & 534 (8.12) & $1.51(1.46-1.56)$ & 6,535 (7.80) & $1,500(4.57)$ & $1.71^{f}(1.53-1.90)$ & 1.57 (1.50-1.65) & $1.78(1.62-1.95)$ \\
\hline Bipolar & 591 (3.52) & 176 (2.69) & $1.31(1.11-1.55)$ & 1,582 (1.89) & 391 (1.19) & $1.58(1.42-1.77)$ & $1.86(1.70-2.40)$ & $2.25(1.88-2.68)$ \\
\hline Schizophrenia & $151(0.90)$ & $100(1.52)$ & $0.59(0.53-0.65)$ & $634(0.76)$ & $313(0.95)$ & $0.79^{9}(0.69-0.91)$ & 1.19 (1.00-1.42) & 1.59 (1.28-1.99) \\
\hline
\end{tabular}

Abbreviations: $\mathrm{Cl}=$ confidence interval; $\mathrm{MS}=$ multiple sclerosis.

${ }^{a} \chi^{2}$ for interaction between population and sex $=50.4, p<0.0001$.

${ }^{b} \chi^{2}$ for interaction between population and sex $=8.18, p=0.004$.

${ }^{c} \chi^{2}$ for interaction between population and sex $=9.03, p=0.003$.

${ }^{d} \chi^{2}$ for interaction between population and sex $=4.07, p=0.04$.

${ }^{e} \chi^{2}$ for interaction between population and sex $=8.33, p=0.004$.

${ }^{f} \chi^{2}$ for interaction between population and sex $=5.07, p=0.02$.

${ }^{9} \chi^{2}$ for interaction between population and $\operatorname{sex}=4.06, p=0.04$. 


\begin{tabular}{|llll|}
\hline Table 4 & \multicolumn{3}{l}{$\begin{array}{l}\text { Mean (SD) delay between comorbidity diagnosis and the index date in } \\
\text { the multiple sclerosis (MS) and matched populations }\end{array}$} \\
\hline Comorbidity & MS population & Matched population & $p$ Value \\
Hypertension & $6.11(4.43)$ & $6.21(4.38)$ & 0.22 \\
Diabetes & $6.41(4.84)$ & $6.48(4.37)$ & 0.57 \\
\hline Heart disease & $5.94(4.71)$ & $6.33(4.30)$ & 0.002 \\
Hyperlipidemia & $5.81(4.52)$ & $5.65(4.36)$ & 0.18 \\
Fibromyalgia & $4.56(3.56)$ & $5.57(3.97)$ & 0.0003 \\
Inflammatory bowel disease & $5.31(2.62)$ & $6.45(4.03)$ & 0.0026 \\
Chronic lung disease & $7.12(4.46)$ & $6.90(4.55)$ & 0.002 \\
Epilepsy & $6.22(4.21)$ & $6.65(4.06)$ & 0.0006 \\
Depression & $6.20(4.14)$ & $6.24(4.12)$ & 0.61 \\
Anxiety & $5.34(3.98)$ & $6.06(4.05)$ & 0.0001 \\
\hline Bipolar & $5.61(4.22)$ & $5.83(4.06)$ & 0.21 \\
\hline Schizophrenia & $6.42(4.66)$ & $7.09(4.52)$ & 0.32 \\
\hline
\end{tabular}

highest rate ratios observed for physical comorbidities were seen for fibromyalgia, inflammatory bowel disease, and epilepsy.

Prior work regarding the prevalence of comorbidity at MS diagnosis has been limited. Unlike our findings, a French study based on registrations for 30 chronic long-term illnesses (affections de longue durée [ALD]) suggested that only 3\% of the MS population had comorbid conditions at the time of MS diagnosis. ${ }^{8}$ However, that study was restricted to persons aged $\leq 45$ years, and to conditions that were notified to the ALD. Therefore, several of the comorbidities we studied were not captured, and other comorbidities, such as hypertension and chronic lung disease, had to be severe in the French study, likely underestimating their prevalence. Even among individuals with an age at MS diagnosis < 45 years, we found that nearly $14 \%$ had depression, 11\% had chronic lung disease, and 5\% had hypertension. More in keeping with our findings are the results of a study of 8,983 American participants in the North American Research Committee on Multiple Sclerosis registry. ${ }^{9}$ That study used a selfreport questionnaire rather than prospectively collected administrative data, and found that comorbidity was common at diagnosis, with psychiatric comorbidities affecting 18\% and vascular comorbidities (including diabetes, hypertension, hyperlipidemia, or ischemic heart disease) affecting 14.0\%. ${ }^{\text {? }}$

A case-control study in California found that patients with MS were more likely to have been diagnosed with uveitis and inflammatory bowel disease before MS diagnosis. ${ }^{25}$ Studies of comorbidity among prevalent MS cases are more common and recent systematic reviews of such studies have suggested that among individuals with prevalent MS, comorbid depression, anxiety, bipolar disorder, epilepsy, fibromyalgia, inflammatory bowel disease, ischemic heart disease, and chronic lung disease are more common than expected in MS. ${ }^{26-30}$ Among other chronic inflammatory diseases, such as gout, the burden of comorbidities at diagnosis is also higher than expected. ${ }^{31}$ Specifically, in rheumatoid arthritis, comorbid cardiovascular disease is more common at diagnosis than expected when compared to the general population. ${ }^{32}$

The observed sex differences in comorbidity status are of particular interest. Some were as expected, for example, depression, anxiety, and fibromyalgia were

Table 5 Crude prevalence of comorbidity in the MS population with an index year of 2000 or later compared to matched controls at diagnosis and 5 years before the diagnosis

\begin{tabular}{|c|c|c|c|c|c|c|}
\hline Comorbidity & \multicolumn{3}{|c|}{ At diagnosis, $\mathrm{n}(\%)$} & \multicolumn{3}{|c|}{5 years before diagnosis, $n(\%)$} \\
\hline Diabetes & $940(6.5)$ & 3,961 (5.5) & $1.18(1.10-1.27)$ & $540(3.7)$ & 2,305 (3.2) & $1.17(1.06-1.28)$ \\
\hline Ischemic heart disease & $985(6.4)$ & 3,809 (5.3) & $1.29(1.20-1.38)$ & $577(4.0)$ & 2,361 (3.3) & $1.22(1.11-1.33)$ \\
\hline Fibromyalgia & 225 (1.5) & 399 (0.55) & $2.81(2.39-3.30)$ & $97(0.67)$ & $206(0.29)$ & $2.34(1.84-2.98)$ \\
\hline Inflammatory bowel disease & $83(0.57)$ & $262(0.36)$ & $1.58(1.23-2.02)$ & $57(0.39)$ & $174(0.24)$ & $1.63(1.21-2.20)$ \\
\hline Chronic lung disease & 2,067 (14.2) & $7,543(10.4)$ & $1.36(1.30-1.43)$ & $1,456(10.0)$ & $6,607(9.1)$ & $1.10(1.04-1.16)$ \\
\hline Epilepsy & $292(2.0)$ & $677(0.94)$ & $2.15(1.87-2.46)$ & $186(1.3)$ & $485(0.67)$ & $1.91(1.61-2.26)$ \\
\hline Schizophrenia & 169 (1.2) & $603(0.84)$ & $1.40(1.18-1.65)$ & $107(0.74)$ & $339(0.47)$ & $1.57(1.27-1.95)$ \\
\hline
\end{tabular}

Abbreviations: $\mathrm{Cl}$ = confidence interval; $\mathrm{MS}=$ multiple sclerosis; $\mathrm{RR}=$ rate ratio. 
more common among women in both populations, and ischemic heart disease was more common in men. However, some of the associations between study population and comorbidity were modified by sex in ways that were not anticipated. In particular, women with MS had a disproportionately higher prevalence of chronic lung disease than did men with MS. In contrast, men with MS had a disproportionately higher prevalence of hypertension, diabetes, and epilepsy and of all of the psychiatric comorbidities studied (depression, anxiety, bipolar disorder, and schizophrenia) than did women with MS when compared to the matched population. The reasons for these findings are uncertain, but sex-based differences in the association between environmental factors and disease risk are recognized. For example, recent studies have suggested that female smokers are biologically more susceptible to chronic obstructive pulmonary disease than male smokers, ${ }^{33}$ possibly due to hormonal effects. Further evaluation of the etiology of these sex-based differences is needed as these findings have implications for managing individuals with MS.

The burden of psychiatric comorbidity for both sexes even at MS diagnosis was striking. While depression and anxiety are recognized to be common in established MS, our findings and those of prior studies collectively indicate that these conditions are the most or nearly the most common preexisting comorbidities at diagnosis, particularly among those aged 20-44 years. ${ }^{8,9}$ Depression and anxiety adversely affect health-related quality of life, adherence to therapy, and the risk of hospitalization. ${ }^{34,35}$ Therefore, our findings suggest that these comorbidities deserve particular clinical attention from the time of diagnosis, and support the need for studies aimed at improved diagnosis and management of these conditions.

Our findings highlight that the burden of comorbidity even at diagnosis is important for clinicians to consider. Clinical trials often exclude individuals with (severe) comorbidities, such that we do not fully understand the efficacy, safety, or tolerability of diseasemodifying therapies in these individuals. For example, it has been observed that individuals with migraine may have more difficulty tolerating one of the most commonly used disease-modifying treatments for MS (interferon- $\beta$ ) due to worsening headache profiles. ${ }^{36}$ Some comorbidities are also known to increase the risk of serious adverse events. For example, diabetes increases the risk of macular edema associated with fingolimod, a recently licensed disease-modifying oral drug for MS. ${ }^{7}$ Therefore, careful assessment of the presence of comorbid conditions is needed when considering such therapies even at the time of diagnosis. Future studies should consider formally evaluating whether treatment safety and effectiveness differs among individuals with the most common comorbidities to better inform clinical practice.

When compared to age-, sex-, and geographically matched controls, most of the comorbidities evaluated were more common in the MS population. The highest rate ratios were observed for fibromyalgia, inflammatory bowel disease, and epilepsy. The presence of one chronic condition may lead to improved ascertainment of comorbid conditions due to increased surveillance by clinicians or increased numbers of contacts with the health care system. Thus, having these conditions may increase the likelihood of getting a diagnosis of MS. Shared genetic or environmental factors may also account for some of the associations observed. For example, shared genetic factors $^{37}$ are associated with MS and inflammatory bowel disease. Vitamin D insufficiency is associated with an increased risk of MS and of ischemic heart disease and diabetes. ${ }^{38}$ Future research should seek to explain the reasons for comorbidity in MS, recognizing they are likely to differ by comorbidity.

It was not feasible to perform this study in all Canadian provinces; however, the provinces studied spanned the country from west to east and included over $40 \%$ of the Canadian population. Since we included a matched control group in each province, we also accounted for the major confounders of age, sex, and region (including regional differences in health service delivery). Use of administrative data that are not collected for research purposes is another limitation but we used case definitions for MS and comorbidity that we had validated previously in 2 provinces. ${ }^{15,20}$ We were unable to assess all relevant comorbidities, including conditions such as cancer, for which important gaps in the epidemiology persist, ${ }^{39}$ including the prevalence at MS diagnosis. However, we assessed the prevalence of multiple comorbidities and focused on comorbidities that could be accurately assessed using administrative data, and that are frequent enough to be relevant at the population level. The mean age at MS diagnosis was 44 years, which appears slightly older than expected; however, we excluded individuals under age 20 years, which would have led to a higher mean age at diagnosis. We cannot exclude the possibility that some of the cases identified were prevalent not incident. Bias in the age at diagnosis is possible but previously we showed that age at the time of the incident MS-related claim is within 1 year of diagnosis date from medical charts in $67 \%$ of cases and within 3 years in $64 \%$ of cases. ${ }^{14}$ Later age at diagnosis may produce higher prevalence estimates for comorbidity but do not affect rate ratios as we matched on age. Moreover, the age-specific estimates showed that comorbidity is common even among those aged 20-44 years at diagnosis. Symptom onset can occur 
years before MS is diagnosed and diagnostic delays have changed over time. Therefore, unrecognized MS symptoms such as fatigue may lead to increased health care utilization before MS diagnosis, ${ }^{23}$ and to increased or earlier diagnosis of comorbidities; however, our findings persisted even 5 years before MS diagnosis. Also, for several conditions, the mean time from diagnosis to the index date was shorter in the MS population. Data regarding the clinical characteristics of the MS participants were lacking such that we could not evaluate the associations of comorbidity with MS characteristics such as disability or disease course; this should be the subject of future research.

Comorbidity is more common than expected in MS, even around the time of diagnosis. The prevalence of psychiatric comorbidity is high, indicating the need for clinical attention to this issue. The observed sexspecific differences in the burden of comorbidity in MS, which differ from those in the matched population, warrant replication and investigation as to etiology.

\section{AUTHOR CONTRIBUTIONS}

Ruth Ann Marrie takes responsibility for the integrity of the data and the accuracy of the data analysis. The analysts and principal investigators at each site had full access to the data at each site (British Columbia: Helen Tremlett, Aruni Tennakoon, Stella Leung; Manitoba: Ruth Ann Marrie, Aruni Tennakoon; Quebec: Christina Wolfson, Bin Zhu; Nova Scotia: John Fisk, Yan Wang). Ruth Ann Marrie, John Fisk, Christina Wolfson, Helen Tremlett, and Sharon Warren designed the study and obtained funding. All authors contributed to the interpretation of the data. Ruth Ann Marrie drafted the manuscript. All authors revised the manuscript and approved of the final version to be published.

\section{ACKNOWLEDGMENT}

All inferences, opinions, and conclusions drawn in this publication are those of the authors and do not reflect the opinions or policies of the Data Stewards. No official endorsement by Manitoba Health, Population Data BC, the Regie D'Assurance Maladie du Quebec, or The Commission d'Accès à l'Information (CAI) of Quebec is intended or should be inferred. Some data used in this report were made available by Health Data Nova Scotia of Dalhousie University. Although this research is based on data obtained from the Nova Scotia Department of Health and Wellness, the observations and opinions expressed are those of the authors and do not represent those of Health Data Nova Scotia or the Department of Health and Wellness. The authors thank Aruni Tennakoon (University of Manitoba), Bin Zhu (McGill University), Yan Wang (Dalhousie University), and Stella Leung (University of Manitoba) for statistical analyses.

\section{STUDY FUNDING}

Supported in part by the Canadian Institutes of Health Research (CIBG 101829), the Rx \& D Health Research Foundation, a Don Paty Career Development award from the Multiple Sclerosis Society of Canada (to R.A.M.), a Manitoba Research Chair from Research Manitoba (to R.A.M.), and a Canada Research Chair in Neurological Health Services Research (to N.J.). The funding sources had no role in the study design, collection, analysis or interpretation of data, or in the decision to submit the article for publication.

\section{DISCLOSURE}

R.A. Marrie receives research funding from Canadian Institutes of Health Research, Research Manitoba, Multiple Sclerosis Society of Canada, Multiple Sclerosis Scientific Foundation, National Multiple Sclerosis Society, and Rx \& D Health Research Foundation, and has conducted clinical trials funded by Sanofi-Aventis. S. Patten has received honoraria for reviewing investigator-initiated grant applications submitted to Lundbeck and Pfizer and has received speaking honoraria from Teva and Lundbeck. $\mathrm{He}$ is the recipient of a salary support award (Senior Health Scholar) from Alberta Innovates, Health Solutions, and receives research funding from the Canadian Institutes for Health Research, Alberta Health Services, and the Alberta Collaborative Research Grants Initiative. H. Tremlett is funded by the Multiple Sclerosis Society of Canada (Don Paty Career Development Award) and is a Michael Smith Foundation for Health Research Scholar and the Canada Research Chair for Neuroepidemiology and Multiple Sclerosis. She has received research support from the National Multiple Sclerosis Society, the Canadian Institutes of Health Research, and the UK MS Trust; and speaker honoraria and/or travel expenses to attend conferences from the Consortium of MS Centres (2013), the National MS Society $(2012,2014)$, Bayer Pharmaceuticals (2010), Teva Pharmaceuticals (2011), ECTRIMS (2011, 2012, 2013, 2014), UK MS Trust (2011), the Chesapeake Health Education Program, US Veterans Affairs (2012), Novartis Canada (2012), Biogen Idec (2014), and American Academy of Neurology (2013, 2014, 2015). Unless otherwise stated, all speaker honoraria are either donated to an MS charity or to an unrestricted grant for use by her research group. C. Wolfson receives research funding from the Multiple Sclerosis Society of Canada, Canadian Institutes of Health Research, Canada Foundation for Innovation, and the National Multiple Sclerosis Society. She has received a speaking honorarium from Novartis Pharmaceuticals. S. Warren receives research funding from the CIHR. L. Svenson reports no disclosures relevant to the manuscript. N. Jette receives funding from CIHR, Alberta Health, Alberta Innovates Health Solutions, University of Calgary, and Alberta Health Services. She also holds an operating grant co-funded by the University of Calgary Hotchkiss Brain Institute and Pfizer Canada. J. Fisk receives funding from the Canadian Institutes of Health Research, MS Society of Canada, and National Multiple Sclerosis Society. Go to Neurology.org for full disclosures.

Received May 24, 2015. Accepted in final form November 16, 2015.

\section{REFERENCES}

1. Baumeister $\mathrm{H}$, Balke K, Härter M. Psychiatric and somatic comorbidities are negatively associated with quality of life in physically ill patients. J Clin Epidemiol 2005;58: 1090-1100.

2. Braunstein JB, Anderson GF, Gerstenblith G, et al. Noncardiac comorbidity increases preventable hospitalizations and mortality among Medicare beneficiaries with chronic heart failure. J Am Coll Cardiol 2003;42:1226-1233.

3. Vendrame M, Auerbach S, Loddenkemper T, Kothare S, Montouris G. Effect of continuous positive airway pressure treatment on seizure control in patients with obstructive sleep apnea and epilepsy. Epilepsia 2011;52:e168-e171.

4. Marrie RA, Horwitz RI, Cutter G, Tyry T, Campagnolo D, Vollmer T. Comorbidity delays diagnosis and increases disability at diagnosis in MS. Neurology 2009;72:117-124.

5. Marrie RA, Rudick R, Horwitz R, et al. Vascular comorbidity is associated with more rapid disability progression in multiple sclerosis. Neurology 2010;74:1041-1047.

6. Marrie RA, Reider N, Cohen J, et al. A systematic review of the incidence and prevalence of comorbidity in multiple sclerosis: overview. Mult Scler 2015;21:263-281.

7. Jain N, Bhatti MT. Fingolimod-associated macular edema: incidence, detection, and management. Neurology 2012; 78:672-680.

8. Fromont A, Binquet C, Rollot F, et al. Comorbidities at multiple sclerosis diagnosis. J Neurol 2013;260: 2629-2637.

9. Marrie RA, Horwitz RI, Cutter G, Tyry T, Vollmer T. Association between comorbidity and clinical characteristics of MS. Acta Neurol Scand 2011;124:135-141. 
10. Health Information Management Branch. Population Report. Winnipeg, Canada: Manitoba Health and Healthy Living; 2008.

11. British Columbia Ministry of Health [creator]. 2012. Discharge Abstract Database (Hospital Separations) [online]. Available at: http://www.popdata.bc.ca/data. Accessed April 1, 2015.

12. British Columbia Ministry of Health [creator]. 2012. Medical Services Plan (MSP) [online]. Available at: http://www.popdata.bc.ca/data. Accessed April 1, 2015.

13. British Columbia Ministry of Health [creator]. 2012. Consolidation File (MSP Registration \& Premium Billing) [online]. Available at: http://www.popdata.bc.ca/data. Accessed April 1, 2015.

14. Marrie RA, Yu N, Blanchard JF, Leung S, Elliott L. The rising prevalence and changing age distribution of multiple sclerosis in Manitoba. Neurology 2010;74:465-471.

15. Marrie RA, Fisk J, Stadnyk K, et al. The incidence and prevalence of multiple sclerosis in Nova Scotia, Canada. Can J Neurol Sci 2013;40:824-831.

16. Marrie RA, Yu B, Leung $S$, et al. Rising prevalence of vascular comorbidities in MS: validation of administrative definitions for diabetes, hypertension, hyperlipidemia. Mult Scler 2012;18:1310-1319.

17. Marrie RA, Yu BN, Leung $S$, et al. The utility of administrative data for surveillance of comorbidity in multiple sclerosis: a validation study. Neuroepidemiology 2013;40:85-92.

18. Marrie RA, Fisk JD, Yu BN, et al. Mental comorbidity and multiple sclerosis: validating administrative data to support population-based surveillance. BMC Neurol 2013;13:16

19. Marrie RA, Yu BN, Leung $S$, et al. Prevalence and incidence of ischemic heart disease in multiple sclerosis: a population-based validation study. Mult Scler Relat Disord 2013;2:355-361.

20. Marrie RA, Fisk JD, Stadnyk KJ, et al. Performance of administrative case definitions for comorbidity in multiple sclerosis in Manitoba and Nova Scotia. Chronic Dis Inj Can 2014;34:145-153.

21. National Diabetes Surveillance System. Responding to the Challenge of Diabetes in Canada [online]. 2003. Available at: http://publications.gc.ca/collections/Collection/H39-421-2003E.pdf. Accessed January 10, 2006.

22. Rothman KJ, Greenland S, eds. Modern Epidemiology, 2nd ed. Philadelphia: Lippincott Williams \& Wilkins; 1998.

23. Marrie RA, Yu N, Wei Y, Elliott L, Blanchard J. High rates of physician services utilization at least five years before multiple sclerosis diagnosis. Mult Scler 2013;19: 1113-1119.

24. Broemeling A, Watson DE, Prebtani F; on behalf of the Councillors of the Health Outcomes Steering Committee of the Health Council of Canada. Population patterns of chronic health conditions, co-morbidity and health care use in Canada: implications for policy and practice. Healthc Q 2008;11:70-76.
25. Langer-Gould A, Albers K, Van Den Eeden S, Nelson L. Autoimmune diseases prior to the diagnosis of multiple sclerosis: a population-based case-control study. Mult Scler 2010;16:855-861.

26. Marrie RA, Reider N, Cohen J, et al. A systematic review of the incidence and prevalence of autoimmune disease in multiple sclerosis. Mult Scler J 2014;21:282-293.

27. Marrie RA, Reider N, Cohen J, et al. A systematic review of the incidence and prevalence of cardiac, cerebrovascular and peripheral vascular disease in multiple sclerosis. Mult Scler 2015;21:318-331.

28. Marrie RA, Reider N, Cohen J, et al. The incidence and prevalence of comorbid gastrointestinal, musculoskeletal, ocular, pulmonary, and renal disorders in multiple sclerosis: a systematic review. Mult Scler 2015;21:332-341.

29. Marrie RA, Reider N, Cohen J, et al. A systematic review of the incidence and prevalence of sleep disorders and seizure disorders in multiple sclerosis. Mult Scler 2015; 21:342-349.

30. Marrie RA, Reider N, Cohen J, et al. The incidence and prevalence of psychiatric disorders in multiple sclerosis: a systematic review. Mult Scler 2015;21:305-317.

31. Kuo CF, Grainge MJ, Mallen C, Zhang W, Doherty M. Comorbidities in patients with gout prior to and following diagnosis: case-control study. Ann Rheum Dis 2014;75: 210-217.

32. Kerola AM, Kerola T, Kauppi MJ, et al. Cardiovascular comorbidities antedating the diagnosis of rheumatoid arthritis. Ann Rheum Dis 2013;72:1826-1829.

33. Sin DD, Cohen SB, Day A, Coxson H, Pare PD. Understanding the biological differences in susceptibility to chronic obstructive pulmonary disease between men and women. Proc Am Thorac Soc 2007;4:671-674.

34. Benito-Leon J, Morales JM, Rivera-Navarro J. Healthrelated quality of life and its relationship to cognitive and emotional functioning in multiple sclerosis patients. Eur J Neurol 2002;9:497-502.

35. Marrie RA, Elliott L, Marriott J, Cossoy M, Tennakoon A, Yu N. Comorbidity increases the risk of hospitalizations in multiple sclerosis. Neurology 2015;84:350-358.

36. Patti F, Nicoletti A, Pappalardo A, et al. Frequency and severity of headache is worsened by Interferon- $\beta$ therapy in patients with multiple sclerosis. Acta Neurol Scand 2012;125:91-95.

37. Blanco-Kelly F, Matesanz F, Alcina A, et al. CD40: novel association with Crohn's disease and replication in multiple sclerosis susceptibility. PLoS One 2010;5:e11520.

38. Pludowski P, Holick MF, Pilz S, et al. Vitamin D effects on musculoskeletal health, immunity, autoimmunity, cardiovascular disease, cancer, fertility, pregnancy, dementia and mortality: a review of recent evidence. Autoimmun Rev 2013;12:976-989.

39. Marrie RA, Reider N, Cohen J, et al. A systematic review of the incidence and prevalence of cancer in multiple sclerosis. Mult Scler 2015;21:294-304. 


\section{Neurology}

Sex differences in comorbidity at diagnosis of multiple sclerosis: A population-based study

Ruth Ann Marrie, Scott B. Patten, Helen Tremlett, et al.

Neurology 2016;86;1279-1286 Published Online before print March 9, 2016

DOI 10.1212/WNL.0000000000002481

This information is current as of March 9, 2016

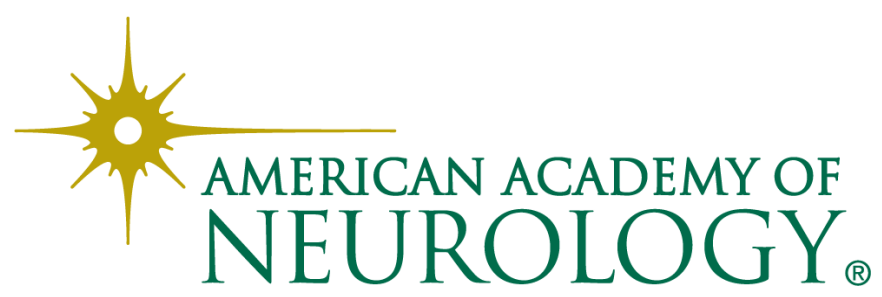




\section{Updated Information \& Services}

\section{Supplementary Material}

\section{References}

\section{Citations}

Subspecialty Collections

\section{Permissions \& Licensing}

\section{Reprints}

including high resolution figures, can be found at: http://n.neurology.org/content/86/14/1279.full

Supplementary material can be found at: http://n.neurology.org/content/suppl/2016/03/09/WNL.0000000000002 481.DC1 http://n.neurology.org/content/suppl/2016/03/09/WNL.0000000000002 481.DC2

http://n.neurology.org/content/suppl/2016/03/09/WNL.0000000000002 481.DC3

This article cites 33 articles, 5 of which you can access for free at: http://n.neurology.org/content/86/14/1279.full\#ref-list-1

This article has been cited by 4 HighWire-hosted articles: http://n.neurology.org/content/86/14/1279.full\#\#otherarticles

This article, along with others on similar topics, appears in the following collection(s):

\section{All Medical/Systemic disease}

http://n.neurology.org/cgi/collection/all_medical_systemic_disease Cohort studies

http://n.neurology.org/cgi/collection/cohort_studies

Multiple sclerosis

http://n.neurology.org/cgi/collection/multiple_sclerosis

Prevalence studies

http://n.neurology.org/cgi/collection/prevalence_studies

Information about reproducing this article in parts (figures,tables) or in its entirety can be found online at:

http://www.neurology.org/about/about_the_journal\#permissions

Information about ordering reprints can be found online:

http://n.neurology.org/subscribers/advertise

Neurology ${ }^{\circledR}$ is the official journal of the American Academy of Neurology. Published continuously since 1951, it is now a weekly with 48 issues per year. Copyright @ 2016 American Academy of Neurology. All rights reserved. Print ISSN: 0028-3878. Online ISSN: 1526-632X.

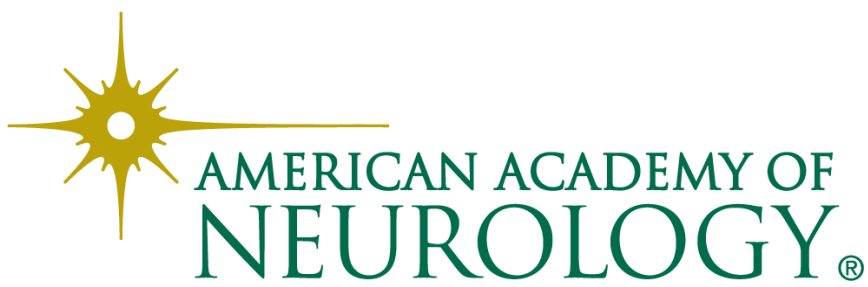

